\title{
Pyrrolinium-substituted Persistent Zwitterionic Ferrocenate De- rivative Enabling the Application of Ferrocene Anolyte
}

\author{
Authors: Hayoung Song ${ }^{1}$, Giyun Kwon ${ }^{2}$, Cooper Citek $^{3}$, Seungwon Jeon ${ }^{1}$, Kisuk Kang, ${ }^{2,4,5 \ddagger}$ and \\ Eunsung Lee ${ }^{1,6 \ddagger}$ \\ Affiliations: \\ ${ }^{1}$ Department of Chemistry, Pohang University of Science and Technology. Pohang, 37673, Republic of Korea. \\ ${ }^{2}$ Department of Materials Science and Engineering, Research Institute of Advanced Materials (RIAM), Seoul National \\ University, 1 Gwanak Road, Seoul 151-742, Republic of Korea. \\ ${ }^{3}$ Division of Chemistry and Chemical Engineering, California Institute of Technology (Caltech), Pasadena, California \\ 91125, United States. \\ ${ }^{4}$ Institute of Engineering Research, College of Engineering, Seoul National University, 1 Gwanak-ro, Gwanak-gu, \\ Seoul 151-742, Republic of Korea. \\ ${ }^{5}$ Center for Nanoparticle Research, Institute of Basic Science, Seoul National University, 1 Gwanak-ro, Gwanak-gu, \\ Seoul 151-742, Republic of Korea. \\ ${ }^{6}$ Division of Advanced Materials Science, Pohang University of Science and Technology. Pohang, 37673, Republic \\ of Korea.
}

\#Correspondence to: eslee@postech.ac.kr (E.L.) and matlgen1@snu.ac.kr (K.K).

ABSTRACT: Here, we report the imidazolium-/pyrrolinium-substituted persistent zwitterionic ferrocenate derivatives, which were characterized by electron paramagnetic resonance (EPR) and ${ }^{57} \mathrm{Fe}$ Mössbauer spectroscopy. Additional theoretical studies on these zwitterionic ferrocenate derivatives clearly explain the origin of their thermal stability and the orbital interactions between iron and imidazolium-/pyrrolinium-substituted zwitterionic cyclopentadienyl ligand. Exploiting the facile $\mathrm{Fe}(\mathrm{II} / \mathrm{I})$ redox chemistry, we successfully demonstrated that the ferrocene derivative can be applied as an example of derivatized ferrocene anolyte for redox-flow batteries. These zwitterionic ferrocenate derivatives will not only deepen our understanding of the intrinsic chemistry of ferrocenate but have the potential to open the way for the rational design of metallocenate derivatives for various applications.

\section{Introduction}

Since its discovery by Pauson, Kealy, ${ }^{1}$ and Miller, ${ }^{2}$ the remarkable stability and reactivity of ferrocene ${ }^{3-4}$ have enabled its use in many applications, including electrochemistry, ${ }^{5}$ medicinal chemistry, ${ }^{6}$ bioorganometallic chemistry, ${ }^{7}$ host-guest chemistry, ${ }^{8}$ and transition metal catalysis. ${ }^{9}$ In particular, the pronounced reversible redox behavior of ferrocene solidifies its position in electrochemistry as a ubiquitous standard. Furthermore, the $\mathrm{Fe}(\mathrm{III}) / \mathrm{Fe}(\mathrm{IV})$ oxidation of ferrocenium has been achieved recently using a superacid medium. ${ }^{10}$

Recently, Mills and co-workers reported fascinating work describing the characterization of a derivatized ferrocenate under low temperature. ${ }^{11}$ Considering that the reduction of ferrocene occurs at highly negative voltages $\left(-3.3 \mathrm{~V} \mathrm{vs} \mathrm{Fc} / \mathrm{Fc}^{+}\right),{ }^{11}$ it can be applied to a wide range of electrochemistry, including the design of anolyte for high energy battery. However, there is still no example of the practical application of ferrocenate derivatives including two intact cyclopentadienyl ligands so far.

Due to the high instability of ferrocenate, the characterization of its chemical properties was possible only at low temperatures. ${ }^{12}$ The decomposition of the ferrocene unit in presence of strong reductants was also reported. ${ }^{13}$ The instability of the ferrocenate is due to the facile dissociation of the cyclopentadienyl anion ligand $(\mathrm{Cp}),{ }^{13}$ as indicated by trapping experiments. ${ }^{14}$ Despite numerous attempts to stabilize the ferrocenate by the introduction of functional groups on the cyclopentadienyl rings, a persistent ferrocenate stable at room temperature could not be obtained (Figure 1a). ${ }^{15-16}$

Based on the fact that their high instability is caused by the dissociation of the cyclopentadienyl ligand, many attempts have been made to synthesize an isolobal structure of ferrocenate stabilized by the introduction of other ligands. ${ }^{17-24}$ Astruc et al. reported the synthesis of an iron-based sandwich complex $\left[\mathrm{Fe}(\mathrm{Cp})\left(\eta^{6}-\mathrm{C}_{6} \mathrm{Me}_{6}\right)\right]^{21}$ and its derivatives. ${ }^{22}$ Tatsumi et al. reported $\left[\left(\mathrm{Cp}^{*}\right) \mathrm{Fe}(\mu\right.$-polyarene $\left.) \mathrm{Fe}\left(\mathrm{Cp}^{*}\right)\right]$ complexes obtained by the reduction of half-sandwich $\mathrm{Fe}(\mathrm{II}) \mathrm{Cp} *$ compounds using potassium polyarenides. ${ }^{23}$ While previous studies on the reduction of heteroferrocenes to obtain stable heteroferrocenate had been unsuccessful, ${ }^{17-19}$ Saito et al. reported the synthesis of stable anionic stannaferrocenate from the reaction between 
$\mathrm{Fe}(\mathrm{acac})_{3}$ and dilithiostannol. ${ }^{24}$ Recently, Goodwin et al. also reported the characterization of low-spin 1,1'-diphosphaferrocenate, which decomposes within 1 hour at room temperature. ${ }^{20}$

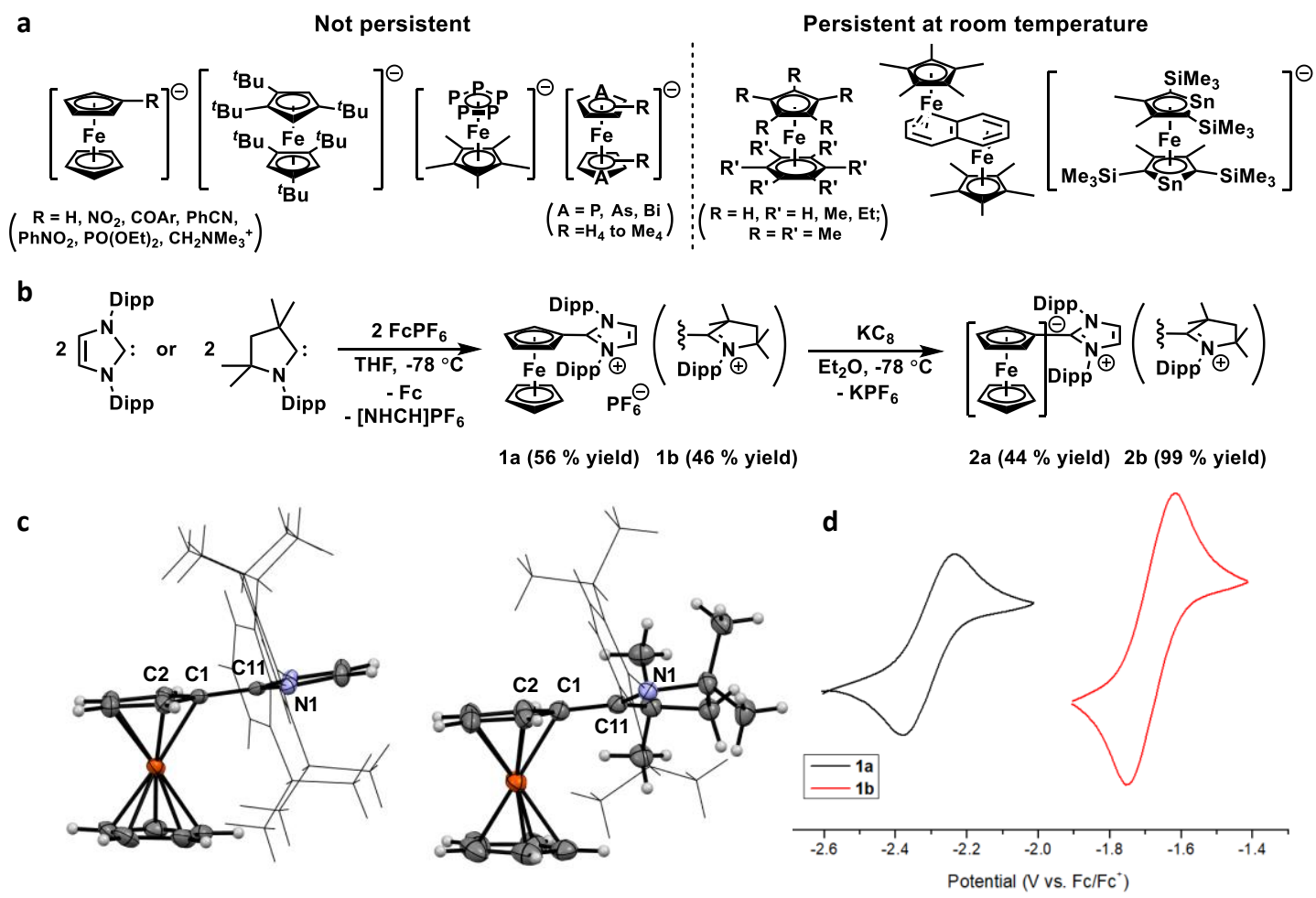

Figure 1 Synthesis of imidazolium-/pyrrolinium-substituted ferrocene derivatives and their zwitterionic ferrocenate derivatives (a) Previous attempts to obtain persistent ferrocenate derivatives and their persistent isolobal structures. (b) Synthesis of $\mathbf{1 a}$ and $\mathbf{1 b}$ by the oxidative nucleophilic substitution of ferrocenium with NHCs and their further reduction to obtain $\mathbf{2 a}$ and $\mathbf{2 b}$, with formal oxidation states indicated. ( $\mathrm{Fc}=$ ferrocenium, Dipp = 2,6-diisopropylphenyl). (c) X-ray crystallographic analysis of $\mathbf{1 a}$ and $\mathbf{1 b}$. (d) Cyclic voltammograms of $\mathbf{1 a}$ and $\mathbf{1 b}$ in $0.1 \mathrm{M}$ of $\left[\mathrm{Bu}_{4} \mathrm{~N}\right] \mathrm{PF}_{6} / \mathrm{MeCN}(\mathrm{vs}$. Fc/Fc', scan rate $=0.1 \mathrm{~V}$ $\left.\mathrm{s}^{-1}\right)$.

Recently, interest in $\mathrm{N}$-heterocyclic carbenes (NHCs) ${ }^{25}$ has increased due to their novel chemical properties, such as the reactivity towards small molecules ${ }^{26-27}$ Especially, their amazing properties to stabilize electron-rich main-group elements, ${ }^{28}$ radicals, ${ }^{29-31}$ and transition-metal centers ${ }^{32}$ are enjoying the spotlight. However, the redox behavior of NHCs remains underexplored, presumably due to the thermal instability of NHC radical ions generated by redox reactions. For example, the radical anion of triazol-5-ylidene was characterized by cyclic voltammetry and electron paramagnetic resonance (EPR) in $1997,{ }^{33}$ but there has been no report of an NHC radical cation produced by one-electron oxidation.

Nevertheless, the reactivity of NHCs with various oxidants has been studied. In 2004, the reactivity of imidazol-2-ylidene with tetracyanoethylene (TCNE) and a ferrocenium salt was reported by Clyburne et al. ${ }^{34}$ They showed that TCNE reacted with the NHC to produce a cationic dimer, formation of which was considered as evidence of an NHC radical cation intermediacy. However, direct observation of the NHC radical cation intermediate was not possible. Subsequently, a potential proton-catalyzed dimerization pathway was suggested as an alternative mechanism for the cationic dimer formation. ${ }^{35}$ This

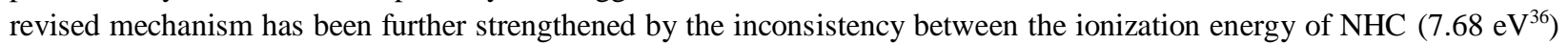
and the electron affinity of TCNE $\left(3.16 \mathrm{eV}^{37}\right)$, as pointed out by the Arduengo group in $2015 .^{38}$ Furthermore, Arduengo ${ }^{38}$ and our group ${ }^{39}$ have also reported various adducts obtained from the reaction between NHCs and TCNE.

Interestingly, Clyburne and coworkers showed that ferrocenium salts react with NHCs to produce imidazolium salts, not dicationic dimers. ${ }^{34}$ They have postulated that the unstable NHC radical cation intermediate likely abstracts a hydrogen atom from the THF solvent. As Arduengo argued, ${ }^{38}$ however, it is necessary to consider whether the charge transfer between an NHC and ferrocenium is thermodynamically feasible. In the light of their respective ionization potentials (NHC: $7.68 \mathrm{eV},{ }^{36}$ ferrocene: $6.81 \mathrm{eV}^{40}$ ), an alternative mechanism is needed to explain how 
the imidazolium salt forms. In addition, various phosphines, which are less nucleophilic than NHCs, were found to react with ferrocenium salts to produce phosphinium-substituted ferrocene derivatives. ${ }^{41}$

Inspired by these works, we speculated that imidazolium-/pyrrolinium-substituted ferrocene derivatives could be formed by the direct reaction of 1,3-bis(2,6-diisopropylphenyl)imidazol-2-ylidene (IPr) and cyclic (alkyl)(amino)carbene (cAAC) with ferrocenium salts. Assuming we could access these imidazolium-/pyrroliniumsubstituted ferrocene derivatives, subsequent reduction yielding zwitterionic ferrocenate derivatives stabilized by the well-known $\pi$-accepting properties and significant steric hindrance of the imidazolium-/pyrrolinium-substituted fragment was considered feasible. Here, we report the successful synthesis of imidazolium-/pyrrolinium-substituted cyclopentadiene iron complexes and elucidation of the unambiguous one-electron reduction of ferrocene derivatives.

\section{Results and discussion}

We sought to investigate the imidazolium salts produced in the reaction of NHCs with ferrocenium salts, as reported by Clyburne ${ }^{16}$ After the addition of IPr to ferrocenium hexafluorophosphate $\left(\mathrm{FcPF}_{6}\right)$ in THF at room temperature, the corresponding imidazolium salt and ferrocene were obtained. ${ }^{34}$ However, we were able to identify an additional component of the reaction mixture that has not been characterized previously. This product was identified as the imidazolium-substituted ferrocenium derivative (1a) and could be cleanly isolated in 56\% yield. In the same manner, pyrrolinium-substituted ferrocenium derivative (1b) was also successfully obtained in $46 \%$ isolated yield using cAAC (Figure 1b).

Compared with the previous studies reported by Kunz ${ }^{42-43}$ and Yuan, ${ }^{44-45}$ imidazolium-substituted ferrocenium derivative with high steric hindrance on imidazolium ring 1a is first reported. Furthermore, although iminium-substituted ferrocene derivatives have previously been reported as carbene precursors, ${ }^{46-51}$ this is also the first report of pyrrolinium-substituted ferrocenium derivative $\mathbf{1 b}$, which exhibits different chemical properties to $\mathbf{1 a}$ due to the greater $\pi$-accepting nature of pyrrolinium compared to imidazolium. The stability of these imidazolium-/pyrrolinium-substituted ferrocene derivatives may further enable research on ferrocene-based carbocation species, ${ }^{52}$ limited by dimerization pathways and dissociation of fulvene ligand from iron.

$\mathrm{X}$-ray diffraction studies of $\mathbf{1 a}$ and $\mathbf{1 b}$ confirmed the imidazolium-/pyrrolinium-substituted ferrocene derivatives (Figure 1c). The C1-C11 bond lengths of $\mathbf{1 a}(1.447(6) \AA)$ and $\mathbf{1 b}(1.446(2) \AA)$ are similar to Yuan's system $\left(1.437(9) \AA^{44}\right)$. 1a exhibits planarity across the cyclopentadiene and imidazolium rings $\left(\mathrm{C} 2-\mathrm{C} 1-\mathrm{C} 11-\mathrm{N} 1=0.81^{\circ}\right)$, in contrast to the distorted structures of $\mathbf{1 b}$ and Yuan's system $\left(17.22^{\circ}\right.$ and $38.83^{\circ 45}$ ) due to the 1,3-allylic strain between the imidazolium and $\mathrm{Cp}$ rings.

To understand the formation of the imidazolium-/pyrrolinium-substituted ferrocene derivatives, we investigated three possible initial reaction pathways by density functional theory (DFT) calculations: ${ }^{41,53}$ (1) Oxidation of NHC by ferrocenium, (2) deprotonation of ferrocenium by NHC, and (3) nucleophilic addition of NHC to ferrocenium (Figure S2 and S3). The computational studies indicate that the nucleophilic addition of NHC to ferrocenium is the most favorable reaction pathway, consistent with the previously reported reaction between ferrocenium and phosphines. ${ }^{41}$ Due to the strong nucleophilicity of $\mathrm{NHC}$, the activation barrier toward the nucleophilic addition of an NHC may be a much as $16 \mathrm{kcal} \mathrm{mol}^{-1}$ lower than the reaction with a phosphine. ${ }^{41}$

The UV-Vis spectra of $\mathbf{1 a}$ and $\mathbf{1 b}$ are shown in Figure S10. In the visible light region, $\mathbf{1 a}$ and $\mathbf{1 b}$ show strong transitions at $471 \mathrm{~nm}\left(\varepsilon=2200 \mathrm{~cm}^{-1} \mathrm{M}^{-1}\right)$ and $551 \mathrm{~nm}\left(\varepsilon=5500 \mathrm{~cm}^{-1} \mathrm{M}^{-1}\right)$, respectively. Time-dependent DFT calculations of $\mathbf{1 a}$ and $\mathbf{1 b}$ at B3PW91/Def2-SVP level of theory predict a metal-to-ligand charge transfer (MLCT) in relatively good agreement with the experimental spectra (Figure S8 and S9). Interestingly, the differences in the transition energies were largely dependent on the LUMO orbitals, which are strongly influenced by the vacant p-orbital at the imidazolium and pyrrolinium. Thus, the absorption band of $\mathbf{1 b}$ is red-shifted compared to that of $\mathbf{1 a}$, due to the stronger $\pi$-accepting nature of cAAC than IPr.

$1 \mathbf{a}$ and $1 \mathbf{b}$ exhibit irreversible oxidation near $0.60 \mathrm{~V}$ vs. $\left.\mathrm{Fc} / \mathrm{Fc}^{+}\right)\left(\right.$Figure S13). However, $\mathrm{Fe}(\mathrm{II}) / \mathrm{Fe}(\mathrm{I})$ reduction at $\mathrm{E}_{1 / 2}=-$ $2.31 \mathrm{~V}(\mathbf{1 a})$ and $\mathrm{E}_{1 / 2}=-1.69 \mathrm{~V}(\mathbf{1 b})\left(\mathrm{vs} . \mathrm{Fc} / \mathrm{Fc}^{+}\right)$are reversible under inert conditions (Figure 1d). On the other hand, a reversible reduction of ferrocene is only observed at low temperature $\left(-50{ }^{\circ} \mathrm{C}\right) .{ }^{12}$ The unusual reversible reduction of these imidazolium-/pyrrolinium-substituted ferrocene derivatives might be attributed to the radical stabilization effect of the imidazolium and pyrrolinium moiety ${ }^{29-30}$ with the protection by sterically hindered substituents. To the best of our knowledge, intact ferrocenate derivatives have never been reported due to their low chemical stability. ${ }^{13}$ Thus, we attempted to prepare the reduced imidazolium-/pyrrolinium-substituted ferrocene radicals $\mathbf{2 a}$ and $\mathbf{2 b}$ to confirm the stabilization effect of the imidazolium-/pyrrolinium-substituted cyclopentadienyl ligands on low-valent transition metal centers. Hence, reduction of $\mathbf{1 a}$ and $\mathbf{1 b}$ by $\mathrm{KC}_{8}$ in toluene at $-78{ }^{\circ} \mathrm{C}$ generates deep green and deep purple solutions of $\mathbf{2 a}$ and $\mathbf{2} \mathbf{b}$, respectively (Figure 
1b). The UV-Vis spectra of $\mathbf{2 a}$ and $\mathbf{2 b}$ are shown in Figure S11. The near-infrared (NIR) transition of $\mathbf{2 a}$ at $1036 \mathrm{~nm}$ is consistent with TD-DFT predictions (Figure S7). 2a and $\mathbf{2 b}$ were isolated by removing solvent under vacuum after celite filter of crude solution (2a: $44 \%$ yield, $\mathbf{2 b}$ : $99 \%$ yield). The $\mathbf{2 a}$ and $\mathbf{2 b}$ are stable for several weeks at $-20{ }^{\circ} \mathrm{C}$ as solid and solution phase under an inert atmosphere.

2a and $\mathbf{2 b}$ show relatively high thermal stability in toluene solution at room temperature, as monitored by UV-VisNIR spectroscopy (Figure S12). The remarkable stability of $\mathbf{2 a}$ and $\mathbf{2 b}$ contrasts with previous studies on the reduction of ferrocene and their derivatives. The previously reported ferrocene radical anion showed a short halflifetime of minutes at low temperatures $\left(-50^{\circ} \mathrm{C}\right)^{54}$ and the reduced radical structures of several ferrocene derivatives could only exist with a short half-lifetime from seconds to minutes at room temperature. ${ }^{\mathbf{1 6}}$ On the other hand, 2a and $\mathbf{2 b}$ showed improved stability with a long half-lifetime in hours to days at room temperature (Figure S12).

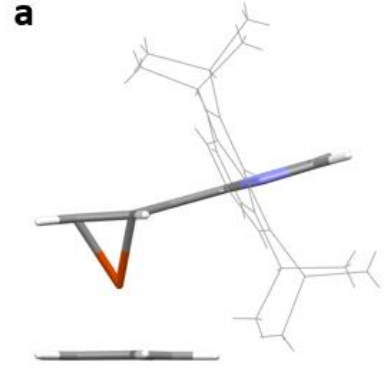

2a

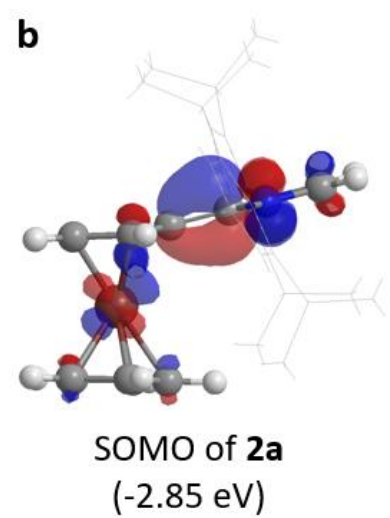

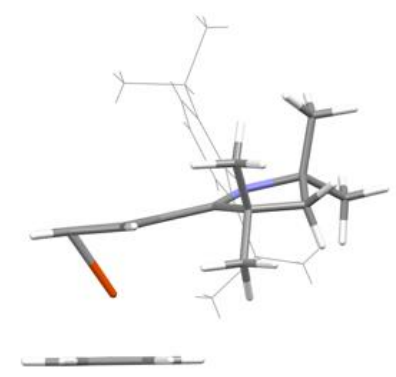

2b

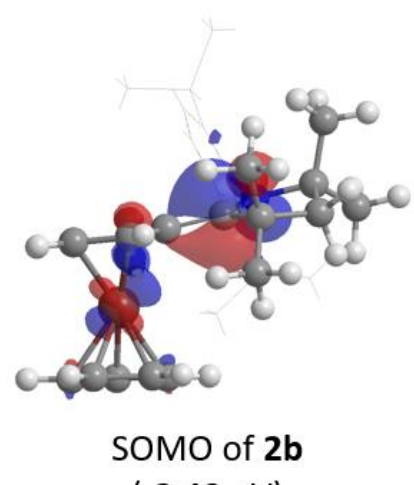

$(-3.49 \mathrm{eV})$
C
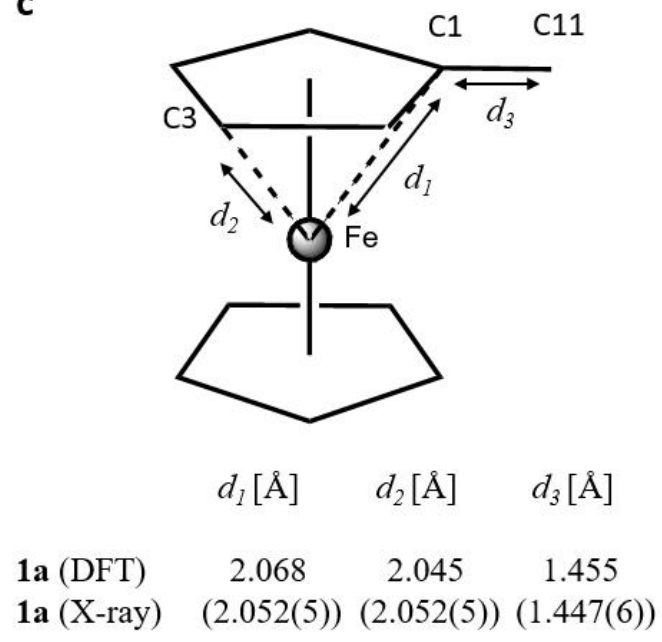

2a (DFT) $\quad 2.243 \quad 2.020 \quad 1.406$

1b (DFT) $2.084 \quad 2.053 \quad 1.447$

1b (X-ray) (2.056(2)) (2.058(2)) (1.446(2))

2b (DFT) $\quad 2.197 \quad 2.026 \quad 1.421$

Figure 2 Structural characterization of zwitterionic ferrocenate derivatives with DFT-calculations (a) Optimized structures of $\mathbf{2 a}$ and $\mathbf{2 b}$ obtained using Gaussian 09W at B3PW91/Def2-SVP level. (b) SOMO of $\mathbf{2 a}$ and $\mathbf{2 b}$ (isovalue $=0.05$ (electrons $/$ bohr $\left.^{3}\right)^{1 / 2}$ ). (c) Selected bond lengths of $\mathbf{1 a}, \mathbf{2 a}, \mathbf{1 b}$, and $\mathbf{2} \mathbf{b}$.

The structures of $\mathbf{2} \mathbf{a}$ and $\mathbf{2} \mathbf{b}$ are evaluated by DFT optimization (Figure 2a). Interestingly, $\mathbf{2} \mathbf{a}$ and $\mathbf{2 b}$ show a slight distortion of the imidazolium-/pyrrolinium-substituted cyclipentadienyl ligand (Figure $\mathbf{2 b}$ ). The results might be explained by inspection of the half-filled SOMO orbitals of $\mathbf{2 a}$ and $\mathbf{2 b}$ showing anti-bonding character between Fe and $\mathrm{C} 1$ (Figure 2c). The bond length between $\mathrm{Fe}-\mathrm{C} 1$ in $\mathbf{2 b}$ is shorter than that in $\mathbf{2 a}$, presumably because the SOMO population in the $\pi$-orbital (between $\mathrm{C} 1-\mathrm{C} 11$ ) is more localized on $\mathrm{C} 11$ in $\mathbf{2 b}$ than it is in 2a. We believe that the SOMO localization on the imidazolium and pyrrolinium moiety accounts for the bonding in $\mathbf{2} \mathbf{a}$ and $\mathbf{2} \mathbf{b}$ and explains the thermal stability of the reduced species. Despite the increase in the length of $\mathrm{Fe} 1-\mathrm{C} 1$ and the decrease in the length of $\mathrm{C} 1-\mathrm{C} 11$ bond, the bond between Fe1 and $\mathrm{C} 1$ is still present and the $\mathrm{C} 1-\mathrm{C} 11$ bond remains in a single bond range. Thus, the imidazolium-/pyrrolinium-substituted cyclipentadienyl ligand ligands of $\mathbf{2 a}$ and $\mathbf{2} \mathbf{b}$ still resemble the previously reported their zwitterionic structures ${ }^{42}$ but differ significantly from the structures of iron $\eta^{4}$-fulvene complexes ${ }^{55}$.

For a clear classification as cyclopentadienide, we also considered the bond-length alternation (BLA) parameter of several fulvene derivatives including 1a, 1b, 2a, and $\mathbf{2 b}$ (Figure S1). In the case of intact fulvenes A and B, their BLA parameters are 11.9, which was close to polyethylene ( 12). On the other hand, the BLA parameters of zwitterionic cyclopentadienide are low (C-4.0 and D-2.1). Interestingly, the fulvene complex (E-H) showed a lower value (6.7-3.7) than intact fulvene (A, B), but still showed a higher value, which could be classified as a fulvene, than zwitterionic cyclopentadienide D. On the 
other hand, 1a, 1b, $\mathbf{2 a}$, and $\mathbf{2 b}$ showed low values of BLA parameters $(0.9-2.7)$, which show a similar value with ferrocenyl carbocation $(\mathbf{I}, \mathbf{J})$. Thus, The ligands of $\mathbf{2 a}$ and $\mathbf{2} \mathbf{b}$, as well as $\mathbf{1 a}$ and $\mathbf{1 b}$, can be classified as cyclopentadienide.

Furthermore, the thermal stability of $\mathbf{2 a}$ and $\mathbf{2 b}$ may in part be attributable to the spin delocalization from iron to the imidazolium and pyrrolinium as calculated by DFT at the B3PW91/Def2-SVP level of theory. The Mulliken atomic spin densities of $\mathbf{2 a}$ and $\mathbf{2 b}$ localize on the iron atom at $46 \%$ and $32 \%$ and in the empty p-orbital of the imidazolium and pyrrolinium at $31 \%$ and $58 \%$, respectively (Figure S5). This result shows that the zwitterionic character of $\mathbf{2 a}$ is larger than that of $\mathbf{2} \mathbf{b}$.
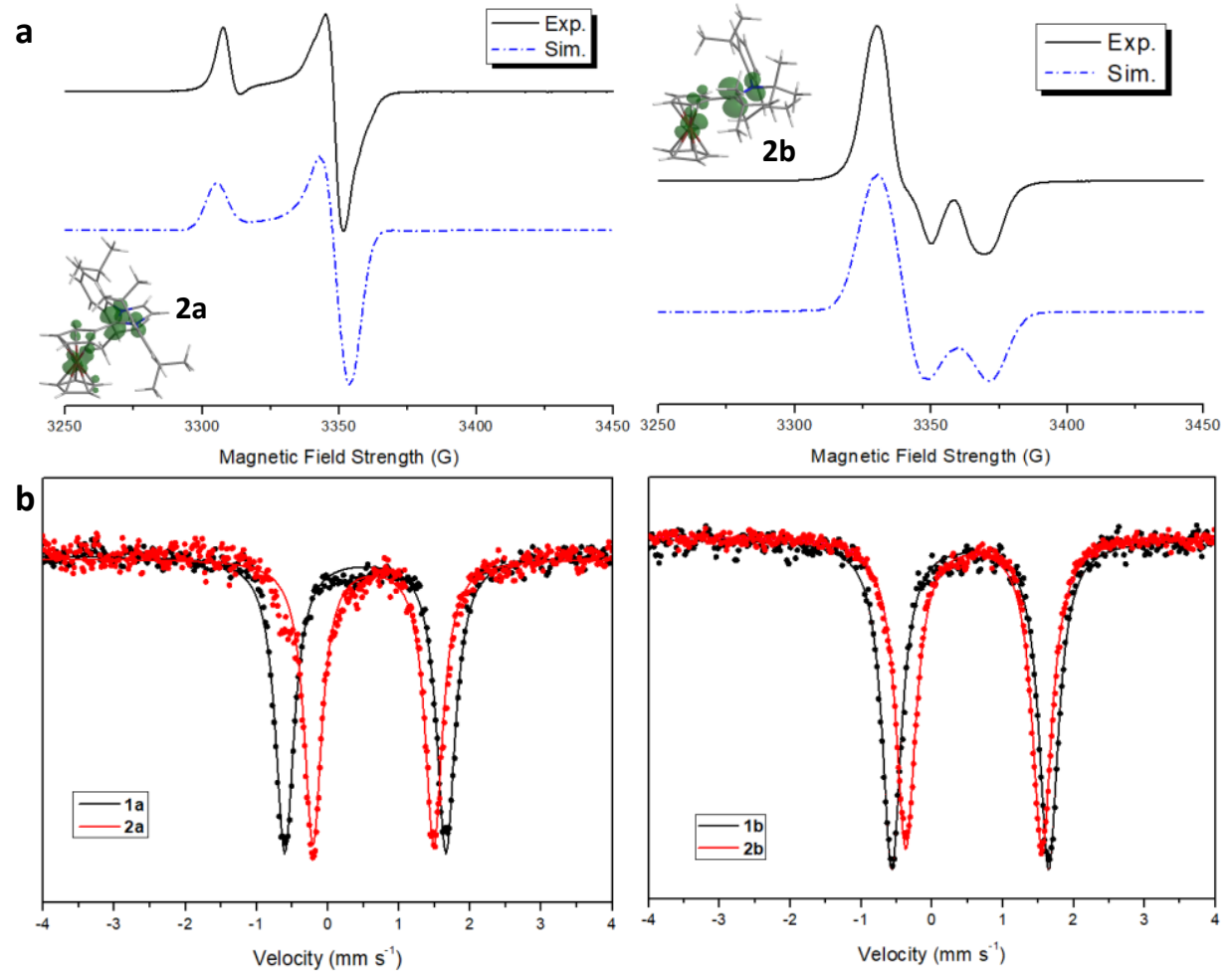

Figure 3 Spectroscopic characterization of zwitterionic ferrocenate derivatives (a) X-band EPR spectrum of $\mathbf{2 a}$ and $\mathbf{2 b}$ in toluene at $160 \mathrm{~K}$ and the visualization of Mulliken spin densities of $\mathbf{2 a}$ and $\mathbf{2 b}$ (Gaussian 09W, B3PW91/Def2-SVP, isovalue $=0.05\left(\text { electrons } / \text { bohr }^{3}\right)^{1 / 2}$ ). (b) Frozen solution Mössbauer spectra of $\mathbf{1 a}, \mathbf{1 b}, \mathbf{2} \mathbf{a}$, and $\mathbf{2 b}$ collected at $80 \mathrm{~K}$ in the presence of a $50 \mathrm{mT}$ parallel magnetic field.

Unlike anionic derivatized ferrocene ${ }^{11}$ and stannaferrocene ${ }^{24}$ showing high-spin states $(\mathrm{S}=3 / 2)$, the X-band EPR spectroscopy data also confirm the low spin, iron-based ground states $(S=1 / 2)$ of $\mathbf{2 a}(\mathrm{g}=[2.040,2.014,2.010])$ and $\mathbf{2 b}(\mathrm{g}=[2.027$, 2.019, 2.000]) (Figure 3a). The EPR spectra of $\mathbf{2 a}$ and $\mathbf{2 b}$ distinctly differ from the data obtained for "ferrocene-substituted radical anions," which exhibit narrow signals with well-resolved ${ }^{1} \mathrm{H}$ couplings and symmetry for the center of the spectra. ${ }^{16}$ Similar to other low-spin $\mathrm{Fe}^{\mathrm{I}}$ complexes $^{56}$ including 1,1-diphosphaferrocenate, ${ }^{20}$ the slightly rhombic spectra of $\mathbf{2 a}$ and $\mathbf{2 b}$ with comparatively wider and anisotropic signals are consistent with iron d-orbital character of the $S=1 / 2$ ground state.

We also performed ${ }^{57} \mathrm{Fe}$ Mössbauer spectroscopy of each compound in benzene or toluene solutions (Figure 3b). The ${ }^{57} \mathrm{Fe}$ Mössbauer spectra of $\mathbf{1 a}$ and $\mathbf{1 b}$ at $80 \mathrm{~K}$ feature symmetric quadrupole doublets at $\delta=0.53 \mathrm{~mm} \mathrm{~s}{ }^{-1}(\mathbf{1 a})$ and $0.54 \mathrm{~mm} \mathrm{~s}^{-1}(\mathbf{1 b})$ (compared to ferrocene at approximately $0.53 \mathrm{~mm} \mathrm{~s}^{-1}$ ) and quadrupole splitting $\Delta \mathrm{E}_{\mathrm{Q}}=2.27$ $\mathrm{mm} \mathrm{s}^{-1}$ (1a) and $2.22 \mathrm{~mm} \mathrm{~s}^{-1}$ (1) $)$ (cf. $2.40 \mathrm{~mm} \mathrm{~s}^{-1}$ for ferrocene). ${ }^{57}$ However, the spectra of their reduced forms $2 \mathbf{a}$ and $\mathbf{2 b}$ are in both cases positively shifted to $\delta=0.64 \mathrm{~mm} \mathrm{~s}^{-1}(\mathbf{2 a})$ and $0.59 \mathrm{~mm} \mathrm{~s}^{-1}(\mathbf{2 b})$ and narrowed to $\Delta \mathrm{E}_{\mathrm{Q}}=$ $1.70 \mathrm{~mm} \mathrm{~s}^{-1}(\mathbf{2 a})$ and $1.92 \mathrm{~mm} \mathrm{~s}^{-1}(\mathbf{2 b})$. The Mössbauer parameters for all four compounds are well-reproduced by a calibrated DFT method (see Supplementary Materials), and single-point calculations recapitulate the shared electron density between iron and the imidazolium and pyrrolinium. The Mössbauer parameters of $2 \mathbf{a}$ and $2 \mathbf{b}$ can be also indirectly validated by comparison with the similar quadrupole doublets of 1,1 '-diphosphaferrocenate $(\delta=$ $0.65 \mathrm{~mm} \mathrm{~s}^{-1}, \Delta \mathrm{E}_{\mathrm{Q}}=1.28 \mathrm{~mm} \mathrm{~s}^{-1}$ at $\left.120 \mathrm{~K}\right)$ and isolobal bis-Fe(I) sandwich complexes reported by Astruc et al. $(\delta=$ $0.56-0.66 \mathrm{~mm} \mathrm{~s}^{-1}$ and $\Delta \mathrm{E}_{\mathrm{Q}}=1.31-1.66 \mathrm{~mm} \mathrm{~s}^{-1}$ between 10 and $\left.260 \mathrm{~K}\right)^{22}$ and Tatsumi et al. $(\delta=0.59 \mathrm{~mm} \mathrm{~s}$ and 
$\Delta \mathrm{E}_{\mathrm{Q}}=1.55-1.59 \mathrm{~mm} \mathrm{~s}^{-1}$ at $\left.90 \mathrm{~K}\right) .{ }^{23}$ On the other hand, $\mathrm{Fe}(\mathrm{I})-\mathrm{CpFe}\left(\mathrm{C}_{6} \mathrm{H}_{6}\right)$ exhibits a quadrupole doublet near $\delta=$ $0.92-0.87 \mathrm{~mm} \mathrm{~s}^{-1}\left(\Delta \mathrm{E}_{\mathrm{Q}}=1.20-0.95 \mathrm{~mm} \mathrm{~s}^{-1}\right.$ between 4.2 and $\left.260 \mathrm{~K}\right)$, potentially excluding decomposition of the reduced products $\mathbf{2 a}$ and $\mathbf{2 b}$ to similar solvent adducts. ${ }^{21}$ An increase in the measured isomer shift would be expected with a slight elongation of the $\mathrm{Fe}-\mathrm{C}$ bonds in the complexes upon reduction; the narrowing of the quadrupole splitting is consistent with increased electron density in axial $\mathrm{d}_{\mathrm{xz}} / \mathrm{d}_{\mathrm{yz}}$-based SOMO orbitals orthogonal to the equatorial $d_{x y} / d_{x 2-y 2} \mathrm{HOMO}$ orbitals of Fe(II) in $\mathbf{1 a}$ and $\mathbf{1 b} .{ }^{58}$ This investigation of the electronic environment of zwitterionic ferrocenate derivatives $\mathbf{2 a}$ and $\mathbf{2 b}$ supports the iron-based spin and lower valence state of $\mathbf{2 a}$ and $\mathbf{2 b}$ with respect to $\mathbf{1 a}$ and $\mathbf{1 b}$.

a

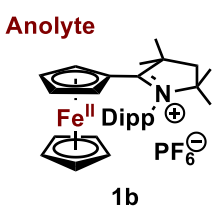

Catholyte
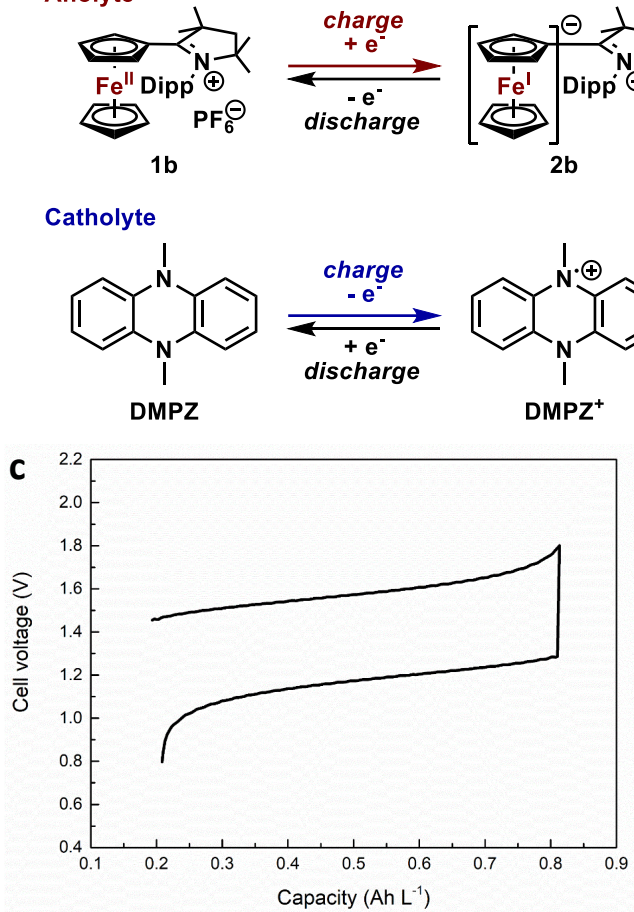

2b b
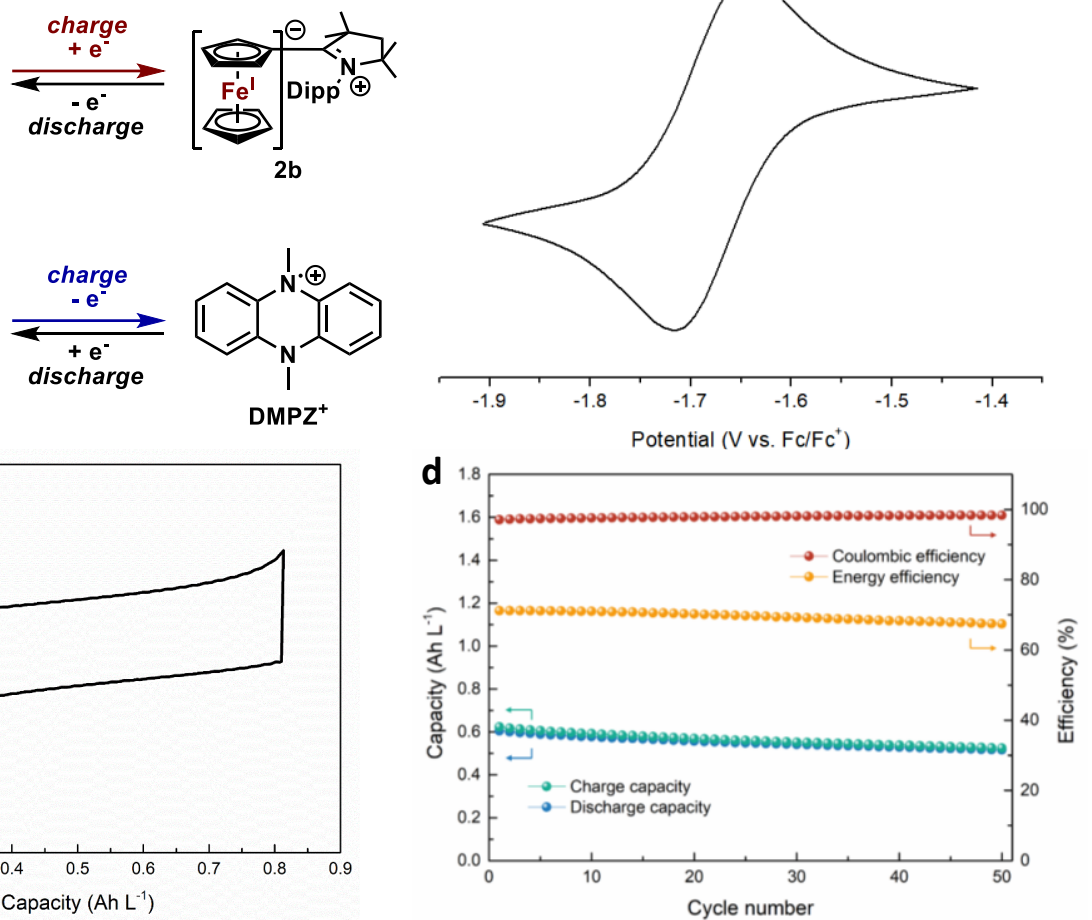

Figure 4 Application of zwitterionic ferrocenate derivatives in redox-flow battery (a) Redox mechanism of $\mathbf{1 b}$ and DMPZ in a flow cell. (b) Cyclic voltammogram of $\mathbf{1 b}$ in $0.5 \mathrm{M} \mathrm{LiTFSI} / \mathrm{MeCN}$ (vs. $\mathrm{Fc} / \mathrm{Fc}^{+}$, scan rate $=0.1 \mathrm{~V} \mathrm{~s}^{-1}$ ). (c) Cell voltage vs. cell capacity. (d) Cycling efficiencies and capacities with 50 cycles.

Most applications of ferrocene derivatives have been limited to their oxidation chemistry due to the instability of the ferrocenate derivatives generated at extremely negative potential. ${ }^{59}$ However, we found that $\mathbf{1 b}$, which exhibits a reversible $\mathrm{Fe}(\mathrm{II}) / \mathrm{Fe}$ (I) redox cycle, could be studied in a redox-flow battery (RFB) system as an example of derivatized ferrocene anolyte. ${ }^{60}$ Considering its remarkable stability, moderate reduction potential $\left(-1.69 \mathrm{~V} \mathrm{vs} \mathrm{Fc} / \mathrm{Fc}^{+}\right.$in $\left.0.1 \mathrm{M}\left[\mathrm{Bu}_{4} \mathrm{~N}\right] \mathrm{PF}_{6} / \mathrm{MeCN}\right)$, and high solubility $(0.561 \mathrm{M})$ in $\mathrm{MeCN}$, we believed that $\mathbf{1 b}$ could serve as a potential anolyte candidate in a high-performance RFB. To construct an all-organic RFB, ${ }^{61}$ commercially available 5,10-dimethyldihydrophenazine (DMPZ) was employed as a counter catholyte material (Figure 4a); DMPZ undergoes a reversible redox reaction at $-0.26 \mathrm{~V} \mathrm{vs}$. $\mathrm{Fc} / \mathrm{Fc}^{+} .62-64$ As shown in Figure $\mathbf{4 b}, \mathbf{1 b}$ in MeCN with 0.5 M LiTFSI supporting electrolyte shows a reversible single-electron redox event at $-1.68 \mathrm{~V}$ vs. $\mathrm{Fc} / \mathrm{Fc}^{+}$, yielding a theoretical cell voltage of $1.42 \mathrm{~V}$ in a flow battery when coupled with DMPZ.

The electrochemical performance of the flow cell employing the DMPZ/1 $\mathbf{b}$ system was also investigated using a customized flow cell (see Supplementary Materials). Figure 4c shows a representative charge-discharge curve at a current density of 20 $\mathrm{mA} \mathrm{cm}{ }^{-2}$. An average cell voltage of $1.40 \mathrm{~V}$ was achieved, consistent with the cyclic voltammetry data. It should be noted that the initial capacity of $0.62 \mathrm{Ah} \mathrm{L}^{-1}$ is reasonably close to the theoretical capacity of $0.80 \mathrm{Ah} \mathrm{L}^{-1}$, indicating material utilization of $\sim 78 \%$. The cycling efficiency and capacity retention data for the RFB indicate that the flow cell maintains a high coulombic efficiency (CE) of $\sim 99 \%$, a voltage efficiency of $\sim 71 \%$, and acceptable energy efficiency (EE) of $\sim 70 \%$ over 50 cycles (Figure 4d). Additionally, stable cycling is maintained in the flow cell without noticeable capacity degradation over 50 cycles, which is mainly attributed to the high stability of $\mathbf{2 b}$ in the solution phase. These results illustrate that 
electrochemistry based on $\mathrm{Fe}(\mathrm{I}) / \mathrm{Fe}(\mathrm{II})$ ferrocene redox couples is feasible in practical battery operation and is enabled by the stereoelectronic stabilization of pyrrolinium-substituted zwitterionic ferrocenate derivative.

\section{Conclusions}

Ferrocene, one of the most representative compounds in the discipline of organometallic chemistry, attracted much attention because of its extremely high thermodynamic, chemical, and Fe(II/III) redox stability. However, the applications using the extremely negative voltage of ferrocene have not been reported to date due to the fast dissociation of the cyclopentadienyl anion ligands from $\mathrm{Fe}(\mathrm{I})$. Thus, an $\mathrm{Fe}(\mathrm{I})$ biscyclopentadiene complex remained elusive for a long time. Here, we have shown that zwitterionic ferrocenate derivatives $\mathbf{2} \mathbf{a}$ and $\mathbf{2} \mathbf{b}$ can be prepared by the one-electron reduction of $\mathbf{1 a}$ and $\mathbf{1 b}$ at ambient conditions, as confirmed by several complementary spectroscopic and theoretical methods. Additionally, a potential application in a redox-flow battery was successfully demonstrated using $\mathbf{1 b}$ as an example of ferrocene anolyte, in part due to the high degree of stabilization of low-valent state by the cAAC moiety. These imidazolium-/pyrrolinium-substituted ferrocene derivatives may deepen our understanding of the electrochemical behavior of ferrocene compounds and open the way to the rational design of ferrocenate derivatives.

\section{ASSOCIATED CONTENT}

Supporting Information. Experimental details, X-ray crystallographic analysis, Computational details, and other characterization data. The crystallographic data for $\mathbf{1 a}$ and $\mathbf{1 b}$ are deposited in the Cambridge Crystallographic Data Centre (CCDC) with deposition numbers CCDC 1940623 and 1940622. This material is available free of charge via the Internet at http://pubs.acs.org.

\section{AUTHOR INFORMATION}

\section{Corresponding Author}

* matlgen1@ snu.ac.kr (K.K), eslee@postech.ac.kr (E.L.)

Notes

The authors declare no competing financial interest.

\section{ACKNOWLEDGMENT}

The X-ray crystallography analysis with synchrotron radiation was performed at the Pohang Accelerator Laboratory (PLS-II BL2D SMC beamline). This work was supported by a National Research Foundation of Korea (NRF) grant funded by the Korean government [Ministry of Science, ICT and Future Planning (MSIP)] (No. NRF-2016H1A2A1907122 - Global Ph.D. Fellowship Program, NRF-2017M3D1A1039553, NRF-2018R1A4A1024713, and NRF-2019M1A2A2067940). We thank Prof. Jonas C. Peters for use of the Mössbauer spectroscopy and Dr. Ewa Pietrasiak for helpful discussions.

\section{REFERENCES}

(1) Kealy, T. J.; Pauson, P. L., A New Type of Organo-Iron Compound. Nature 1951, 168, 1039-1040.

(2) Miller, S. A.; Tebboth, J. A.; Tremaine, J. F., 114. Dicyclopentadienyliron. J. Chem. Soc. 1952, 632-635.

(3) Wilkinson, G.; Rosenblum, M.; Whiting, M. C.; Woodward, R. B., The Structure of Iron Bis-Cyclopentadienyl. J. Am. Chem. Soc. 1952, 74, 2125-2126.

(4) Fischer, E. O.; Pfab, W., Cyclopentadien-Metallkomplexe, Ein Neuer Typ Metallorganischer Verbindungen. Z. Naturforsch. B Chem. Sci. 1952, 7, 377-379.

(5) Gagne, R. R.; Koval, C. A.; Lisensky, G. C., Ferrocene as an Internal Standard for Electrochemical Measurements. Inorg. Chem. 1980, 19, 2854-2855.

(6) Patra, M.; Gasser, G., The Medicinal Chemistry of Ferrocene and Its Derivatives. Nat. Rev. Chem. 2017, 1, 0066.

(7) van Staveren, D. R.; Metzler-Nolte, N., Bioorganometallic Chemistry of Ferrocene. Chem. Rev. 2004, 104, 5931-5986.

(8) Ko, Y. H.; Hwang, I.; Lee, D.-W.; Kim, K., Ultrastable Host-Guest Complexes and Their Applications. Isr. J. Chem. 2011, 51, 506-514.

(9) Gómez Arrayás, R.; Adrio, J.; Carretero, J. C., Recent Applications of Chiral Ferrocene Ligands in Asymmetric Catalysis. Angew. Chem. Int. Ed. 2006, 45, 7674-7715.

(10) Malischewski, M.; Adelhardt, M.; Sutter, J.; Meyer, K.; Seppelt, K., Isolation and Structural and Electronic Characterization of Salts of the Decamethylferrocene Dication. Science 2016, 353, 678-682.

(11) Goodwin, C. A. P.; Giansiracusa, M. J.; Greer, S. M.; Nicholas, H. M.; Evans, P.; Vonci, M.; Hill, S.; Chilton, N. F.; Mills, D. P., Isolation and Electronic Structures of Derivatized Manganocene, Ferrocene and Cobaltocene Anions. Nat. Chem. 2020, 13, 243-248.

(12) Ito, N.; Saji, T.; Aoyagui, S., Electrochemical Formation of Stable Ferrocene Anion and the Formal Rate Constant of the Ferrocene $^{0 /-}$ Electrode. J. Organomet. Chem. 1983, 247, 301-305. 
(13) Trifan, D. S.; Nicholas, L., Reductive Cleavage of Ferrocene. J. Am. Chem. Soc. 1957, 79, 2746-2749.

(14) Brown, A. D.; Reich, H., Reductive Cleavage of Ferrocene Derivatives. J. Org. Chem. 1970, 35, 1191-1193.

(15) Slocum, D. W.; Jones, W. E.; Crimmins, T. F.; Hauser, C. R., Reduction of Ferrocene Methiodides. Synthesis of the Dimethylferrocenes. J. Org. Chem. 1969, 34, 1973-1974.

(16) Elschenbroich, C.; Cais, M., Organometallic Studies Xxix. Electron Spin Resonance of Ferrocene-Substituted Radical Anions. J. Organomet. Chem. 1969, 18, 135-143.

(17) Lemoine, P.; Gross, M.; Braunstein, P.; Mathey, F.; Deschamps, B.; Nelson, J. H., Electrochemistry of Phosphaferrocenes. 1. Comparison of the Redox Properties of Ferrocene, Diphosphaferrocene, 3,4-Dimethyl-1-Phosphaferrocene and 3,3',4,4'Tetramethyl-1,1'-Diphosphaferrocene. Organometallics 1984, 3, 1303-1307.

(18) Ashe, A. J.; Al-Ahmad, S.; Pilotek, S.; Puranik, D. B.; Elschenbroich, C.; Behrendt, A., Comparison of the Properties of Polymethyl-1,1'-Diheteroferrocenes of the Group 15 Elements. Organometallics 1995, 14, 2689-2698.

(19) Winter, R. F.; Geiger, W. E., Electron-Transfer Properties of Cp*FeP5: Evidence for Dimerization Reactions Following Both Oxidation and Reduction. Organometallics 1999, 18, 1827-1833.

(20) Greer, S. M.; Üngor, Ö.; Beattie, R. J.; Kiplinger, J. L.; Scott, B. L.; Stein, B. W.; Goodwin, C. A. P., Low-Spin 1,1'Diphosphametallocenates of Chromium and Iron. Chem. Commun. 2021, 57, 595-598.

(21) Hamon, J. R.; Astruc, D.; Michaud, P., Syntheses, Characterizations, and Stereoelectronic Stabilization of Organometallic Electron Reservoirs: The 19-Electron $\mathrm{d}^{7}$ Redox Catalysts . $\eta^{5}-\mathrm{C}_{5} \mathrm{R}_{5} \mathrm{Fe}_{-} \eta^{6}-\mathrm{C}_{6} \mathrm{R}_{6}^{\prime}$. J. Am. Chem. Soc. 1981, 103, 758-766.

(22) Rabaa, H.; Lacoste, M.; Delville-Desboise, M.-H.; Ruiz, J.; Gloaguen, B.; Ardoin, N.; Astruc, D.; Beuze, A. L.; Saillard, J.Y.; Linares, J., et al., Electronic Interplay between Two Iron Centers across Polyaromatic Ligands: Syntheses, Redox Chemistry, and Electronic Structures of the Electron-Reservoir 36- to 38-Electron Complexes $\left[\left(\mathrm{FeCp}^{*}\right)_{2}\left(\mu_{2}-\eta^{12}-\text { Polyaromatic }\right)\right]^{\mathrm{q}+}(\mathrm{q}=0-2)$ Including Mixed Valences and Biradicals. Organometallics 1995, 14, 5078-5092.

(23) Hatanaka, T.; Ohki, Y.; Kamachi, T.; Nakayama, T.; Yoshizawa, K.; Katada, M.; Tatsumi, K., Naphthalene and Anthracene Complexes Sandwiched by Two $\left\{\left(\mathrm{Cp}^{*}\right) \mathrm{Fe}^{\mathrm{I}}\right\}$ Fragments: Strong Electronic Coupling between the Fe ${ }^{\mathrm{i}}$ Centers. Chem. Asian. J. 2012, 7, 1231-1242.

(24) Saito, M.; Matsunaga, N.; Hamada, J.; Furukawa, S.; Tada, T.; Herber, R. H., Anionic Stannaferrocene and Its Unique Electronic State. Chem. Lett. 2019, 48, 163-165.

(25) Hopkinson, M. N.; Richter, C.; Schedler, M.; Glorius, F., An Overview of N-Heterocyclic Carbenes. Nature 2014, 510 , 485496.

(26) Martin, D.; Soleilhavoup, M.; Bertrand, G., Stable Singlet Carbenes as Mimics for Transition Metal Centers. Chem. Sci. 2011, 2, 389-399.

(27) Song, H.; Kim, Y.; Park, J.; Kim, K.; Lee, E., Activation of Small Molecules at N-Heterocyclic Carbene Centers. Synlett 2016, 27, 477-485.

(28) Nesterov, V.; Reiter, D.; Bag, P.; Frisch, P.; Holzner, R.; Porzelt, A.; Inoue, S., NHCs in Main Group Chemistry. Chem. Rev. 2018, 118, 9678-9842.

(29) Martin, C. D.; Soleilhavoup, M.; Bertrand, G., Carbene-Stabilized Main Group Radicals and Radical Ions. Chem. Sci. 2013, 4, 3020-3030.

(30) Kim, Y.; Lee, E., Stable Organic Radicals Derived from N-Heterocyclic Carbenes. Chem. Eur. J. 2018, 24, $19110-19121$.

(31) Kundu, S.; Sinhababu, S.; Chandrasekhar, V.; Roesky, H. W., Stable Cyclic (Alkyl)(Amino)Carbene (cAAC) Radicals with Main Group Substituents. Chem. Sci. 2019, 10, 4727-4741.

(32) Roy, S.; Mondal, K. C.; Roesky, H. W., Cyclic Alkyl(Amino) Carbene Stabilized Complexes with Low Coordinate Metals of Enduring Nature. Acc. Chem. Res. 2016, 49, 357-369.

(33) Enders, D.; Breuer, K.; Raabe, G.; Simonet, J.; Ghanimi, A.; Stegmann, H. B.; Teles, J. H., A Stable Carbene as П-Acceptor Electrochemical Reduction to the Radical Anion. Tetrahedron Lett. 1997, 38, 2833-2836.

(34) Ramnial, T.; McKenzie, I.; Gorodetsky, B.; Tsang, E. M. W.; Clyburne, J. A. C., Reactions of N-Heterocyclic Carbenes (NHCs) with One-Electron Oxidants: Possible Formation of a Carbene Cation Radical. Chem. Commun. 2004, 1054-1055.

(35) Canal, J. P.; Ramnial, T.; Dickie, D. A.; Clyburne, J. A. C., From the Reactivity of N-Heterocyclic Carbenes to New Chemistry in Ionic Liquids. Chem. Commun. 2006, 1809-1818.

(36) Arduengo, A. J.; Bock, H.; Chen, H.; Denk, M.; Dixon, D. A.; Green, J. C.; Herrmann, W. A.; Jones, N. L.; Wagner, M.; West, R., Photoelectron Spectroscopy of a Carbene/Silylene/Germylene Series. J. Am. Chem. Soc. 1994, 116, 6641-6649.

(37) Khuseynov, D.; Fontana, M. T.; Sanov, A., Photoelectron Spectroscopy and Photochemistry of Tetracyanoethylene Radical Anion in the Gas Phase. Chem. Phys. Lett. 2012, 550, 15-18.

(38) Arduengo III, A. J.; Calabrese, J. C.; Marshall, W. J.; Runyon, J. W.; Schiel, C.; Schinnen, C.; Tamm, M.; Uchiyama, Y., Imidazol-2-Ylidene Reactivity Towards Cyanocarbons. Z. Anorg. Allg. Chem 2015, 641, 2190-2198.

(39) Song, H.; Kim, Y.; Park, J.; Ko, Y. H.; Kim, K.; Lee, E., An N-Heterocyclic-Carbene-Tetracyanoethylene Zwitterion: Experimental and Theoretical Study on Its Formation and Reactivity. Eur. J. Org. Chem. 2017, 1231-1235.

(40) Meot-Ner, M., Ion Chemistry of Ferrocene. Thermochemistry of Ionization and Protonation and Solvent Clustering. Slow and Entropy-Driven Proton-Transfer Kinetics. J. Am. Chem. Soc. 1989, 111, 2830-2834.

(41) Chamkin, A. A.; Krivykh, V. V.; Nikitin, O. M.; Kreindlin, A. Z.; Shteltser, N. A.; Dolgushin, F. M.; Artyushin, O. I.; Ikonnikov, N. S.; Borisov, Y. A.; Belousov, Y. A., et al., Direct Phosphination of Ferrocenium Ion with Tertiary Phosphines by the Mechanism of Oxidative Nucleophilic Substitution. Eur. J. Inorg. Chem. 2018, 4494-4504. 
(42) Kunz, D.; Johnsen, E. Ø.; Monsler, B.; Rominger, F., Highly Ylidic Imidazoline-Based Fulvenes as Suitable Precursors for the Synthesis of Imidazolium-Substituted Metallocenes. Chem. Eur. J. 2008, 14, 10909-10914.

(43) Schmid, D.; Seyboldt, A.; Kunz, D., A Direct Synthesis of a Strongly Zwitterionic 6,6'-Diaminofulvalene. Z. Naturforsch. B Chem. Sci. 2014, 69, 580-588.

(44) Wang, J.; Feng, L.; Ma, F.; Lin, F.; Xie, L.; Yuan, Y., Synthesis, Crystal Structure and Properties of Iodide and Hexafluorophosphate Salts of 2-Ferrocenyl (or Binuclear Ferrocenyl)-1,3-Dialkylbenzimidazolium. Chin. J. Org. Chem. 2012, 32, 1479 - 1486.

(45) Lai, Z.-M.; Ye, H.-M.; Wan, Q.; Xie, L.-L.; Bai, S.; Yuan, Y.-F., Synthesis, Crystal Structure and Properties of BenzimidazoleBridged Dinuclear Ferrocenyl Derivatives. J. Mol. Struct. 2014, 1059, 33-39.

(46) DeHope, A.; Mendoza-Espinosa, D.; Donnadieu, B.; Bertrand, G., A Persistent (Amino)(Ferrocenyl)Carbene. New. J. Chem. 2011, 35, 2037-2042.

(47) Yasue, R.; Miyauchi, M.; Yoshida, K., Planar Chiral Cyclic (Amino)(Ferrocenyl)Carbene as Ligand for Transition Metals. Adv. Synth. Catal. 2017, 359, 255-259.

(48) Shikata, Y.; Yasue, R.; Yoshida, K., Coordination Behavior of a Planar Chiral Cyclic (Amino)(Ferrocenyl)Carbene Ligand in Iridium Complexes. Chem. Eur. J. 2017, 23, 16806-16812.

(49) Yasue, R.; Miyauchi, M.; Yoshida, K., A Planar Chiral Six-Membered Cyclic (Amino)(Ferrocenyl)Carbene and Its Sulfur Adduct. Tetrahedron Asymmetry 2017, 28, 824-829.

(50) Yasue, R.; Yoshida, K., Synthesis and Application of Planar Chiral Cyclic (Amino)(Ferrocenyl)Carbene Ligands Bearing Fecp* Group. Organometallics 2019, 38, 2211-2217.

(51) Takagaki, W.; Yasue, R.; Yoshida, K., Development of Planar Chiral Five-Membered Cyclic (Amino)(Ferrocenylene)Carbene Ligand and Its Iridium Dicarbonyl Complex. Bull. Chem. Soc. Jpn. 2020, 93, 200-204.

(52) Gleiter, R.; Bleiholder, C.; Rominger, F., A-Metallocenylmethylium Ions and Isoelectronic Fulvene Complexes of $\mathrm{d}^{6}$ to $\mathrm{d}^{9}$ Metals. Structural Considerations. Organometallics 2007, 26, 4850-4859.

(53) Babin, V. N.; Belousov, Y. A.; Belousova, T. A.; Borisov, Y. A.; Gumenyuk, V. V.; Nekrasov, Y. S., Reactions of Ferricinium Salts with Lewis Bases. Russ. Chem. Bull. 2011, 60, 2081-2087.

(54) Khrizanforov, M.; Strekalova, S.; Kholin, K.; Khrizanforova, V.; Grinenko, V.; Gryaznova, T.; Budnikova, Y., One-Stage Synthesis of $\mathrm{FcP}(\mathrm{O})\left(\mathrm{OC}_{2} \mathrm{H}_{5}\right)_{2}$ from Ferrocene and A-Hydroxyethylphosphonate. RSC Adv. 2016, 6, 42701-42707.

(55) Edelmann, F.; Lubke, B.; Behrens, U., Pbergangsmetall-Fulven-Komplexe, Xviii. Pber (Fulven)Nickel(0)-Komplexe. Strukturvergleich Von (1,5-Cyclooctadien)(6,6-Diphenylfulven)Nickel Und Tricarbonyl-(6,6-Diphenylfulven)Eisen. Chem. Ber. 1982, 115, 1325-1331.

(56) Rajasekharan, M. V.; Giezynski, S.; Ammeter, J. H.; Oswald, N.; Hamon, J. R.; Astruc, D.; Michaud, P., Epr Studies of the Electronic Structure and Dynamic Jahn-Teller Effect in Iron(I) Sandwich Compounds. J. Am. Chem. Soc. 1982, 104, $2400-2407$.

(57) Good, M. L.; Buttone and, J.; Foyt, D., MöSsbauer Spectroscopy of Metal Sandwich Compounds. Ann. N. Y. Acad. Sci. 1974, 239, 193-207.

(58) Gütlich, P.; Bill, E.; Trautwein, A., MöSsbauer Spectroscopy and Transition Metal Chemistry: Fundamentals and Application. Springer: Berlin, Heidelberg, 2011.

(59) Astruc, D., Why Is Ferrocene So Exceptional? Eur. J. Inorg. Chem. 2017, 2017, 6-29.

(60) Soloveichik, G. L., Flow Batteries: Current Status and Trends. Chem. Rev. 2015, 115, 11533-11558.

(61) Leung, P.; Shah, A. A.; Sanz, L.; Flox, C.; Morante, J. R.; Xu, Q.; Mohamed, M. R.; Ponce de León, C.; Walsh, F. C., Recent Developments in Organic Redox Flow Batteries: A Critical Review. J. Power Sources 2017, 360, 243-283.

(62) Kwon, G.; Lee, S.; Hwang, J.; Shim, H.-S.; Lee, B.; Lee, M. H.; Ko, Y.; Jung, S.-K.; Ku, K.; Hong, J., et al., Multi-Redox Molecule for High-Energy Redox Flow Batteries. Joule 2018, 2, 1771-1782.

(63) Kwon, G.; Lee, K.; Lee, M. H.; Lee, B.; Lee, S.; Jung, S.-K.; Ku, K.; Kim, J.; Park, S. Y.; Kwon, J. E., et al., Bio-Inspired Molecular Redesign of a Multi-Redox Catholyte for High-Energy Non-Aqueous Organic Redox Flow Batteries. Chem 2019, 5 , 2642-2656.

(64) Lee, M.; Hong, J.; Lee, B.; Ku, K.; Lee, S.; Park, C. B.; Kang, K., Multi-Electron Redox Phenazine for Ready-to-Charge Organic Batteries. Green Chem. 2017, 19, 2980-2985. 